\title{
Simple Analysis on Fair Use System of Copyright
}

\author{
Shu-Hui WANG*, Yan-Ping NIU, Cai-Juan SHANG, \\ Sheng-Feng WANG, Fei-Fei SHANG and Zhi-Yuan WU \\ Department of Scientific Research, Academy of Armored Force Engineering, P.R. China, 100072 \\ Email: `Shu-hui WANG, greenleaf999@163.com
}

Keywords: Impactive cutting, Orthogonal experiment, Deposited materials, Remanufacturing.

\begin{abstract}
In a sense, the fair use system of copyright is a restriction to authors' copyright, which aims to maximize the promotion of information exchange and cultural communication on the premise of protecting copyright owners' legitimate interests so as to promote the progress of social civilization. The paper expounded the fair use system's meaning, value orientation and scope of application, analyzed the problems confronted by the current fair use system of copyright and put forward some suggestions on system improvement.
\end{abstract}

\section{Introduction}

The generation of any new works cannot be separated from reference and absorption for human being's existing spiritual civilization, and whether in scientific invention, academic research or literature and art creation process, the existing cultural achievements must be referenced in different extents. By statistics on a lot of manuscripts encountered by authors at work, as $99 \%$ of academic papers referenced theories, ideas or methods in others' published works, the "fair use" system of copyright is inevitably involved in.

\section{Definition on Scope of Fair Use of Copyright}

The so-called "fair use" of copyright means that under specified conditions, when people other than the copyright owners use copyrighted works based on legitimate purposes, they neither obtain the consent from the copyright owners, nor pay to the copyright owners, but need to specify copyright owners' names, works names and works sources and protect other rights enjoyed by the copyright owners. Under normal conditions, nobody is allowed to use the copyright owners' works without permission. However, some behaviors harmless to the copyright and conducive to social benefits are stipulated in the "Copyright Law", which shall not be regarded as infringement. These behaviors are theoretically called "fair use" and also called "free use" in some countries. The scope of "fair use" is defined in Article 22 of "Copyright Law" in details by the way of examples, for example, there are 12 following circumstances that others' published works are used for personal study, research or appreciation; others' published works are properly referenced in works for introduction and comment on a certain work or explanation of a certain problems; others' published works inevitably reappear or referenced for in newspapers, periodicals, radio stations, television stations or other media for the purpose of reporting current news; current affair articles (except for those forbidden to be published and broadcasted by authors) concerning political, economic and religious issues published in other newspapers, periodicals, radio stations, television stations or other media are published or broadcasted in newspapers, periodicals, radio stations, television stations or other media; speeches made in public meetings are published or broadcasted in newspapers, periodicals, radio stations, television stations and other media (except for those forbidden to be published and broadcasted by authors). When others' works are used under the above circumstances, you may not seek the consent from the copyright owners and not pay to the copyright owners. Accordingly, the "fair use" of copyright shall include five meanings that: (1) the use within the scope of "Copyright Law" based on a legal basis; (2) the use based on legitimate purposes, not for profits; (3) the use without consent 
from authors and copyright owners; (4) the use free of charge and without payment; (5) no copyright infringement.

\section{Value Orientation of Fair Use System of Copyright}

The "fair use" system is the most core copyright system, which exists for the purpose of balancing creators, communicators and users' interests and has been widely recognized by various countries in the world. The legislative spirit of the modern copyright law shall seek balance between copyright owners' individual rights and interests and public interests, and in the system construction process, many interest balance means are designed, such as copyright protection period, limited scope of works, statutory licensing system, compulsory licensing system and the like. It shall be said that the fundamental purpose of copyright legislation is not only to protect the copyright owners' rights, but also to protect the public interests that the public is educated and obtains knowledge, and within a certain scope, people can freely use the copyright works. As the most basic content of copyright, the fair use system is gradually improved along with the development of the copyright system, which is in need for interest balance, namely need for balance between copyright owners' interests and users' interests as well as between individual interests and social interests; it aims to give the use rights to the public to a certain extend through protecting obligees' various rights, thereby achieving the goal of promoting social, scientific and cultural development. Therefore, the copyright with exclusive rights shall not impede the dissemination and the use of works in a certain range, and creation is a continuous historical process. The people's creative inspiration benefits from the previous works' enlightenment, many realistic creation materials come from the previous works' contribution, and the authors' exclusive rights shall not be an obstacle to the development of social civilization. This idea originates from western case law countries. As early as 1803, British Executive had thought that the use without permission and payment is "fair" as the future author aims to create new works, so that the scientific and cultural progress is promoted, and the public is benefited. Also as Paterson serving as American scholar said that "as the public dissemination of information is very important, both cause of freedom and democratic society cannot yield to the private monopoly under the traditional copyright concepts".

\section{Limitation of China's Current Fair Use System of Copyright}

As a whole, China's current fair use system of copyright is beneficial to the protection of copyright owners' rights and interests and simultaneously can promote knowledge dissemination and use and better balance interest conflicts between the both. However, there are some defects in some provisions, and particularly, along with network technology development, it has been difficult to fully apply to new situations appearing under network environment.

\section{Defects Exist in the Current Fair Use System of Copyright.}

Firstly, the scope of "fair use" has been defined in China's copyright law by the way of examples, so that there is a clear reference when others other than the copyright owners use the works, and there also is a positive significance in preventing the abuse of "fair use". However, the current fair use system of copyright is lack of flexibility due to specific provisions; all uses may not be included in the examples, so that the individual copyright disputes are hard to effectively resolve; secondly, some regulations on the current fair use system of copyright are more general, and no specific standard is established, for example, there is no regulation that for class teaching in schools or scientific research, the published works are translated or a small amount of published works is copied for use by teachers or scientific research personnel, which cannot be published; "class teaching in schools" generally means that teaching activities in universities, middle schools and primary schools established by the state, which are divided into the scope of "fair use" so as to protect the right that citizens are educated. But, whether class teaching activities in various private training institutions in society belong to the scope of "fair use" or not, no specific regulation is included in the "Copyright Law". In addition, the 
number of "fair use" is not specifically regulated in the current copyright law. Taking the above regulation as an example, the regulation on the word "a small amount" is very fuzzy, and "a small amount" is not specifically described.

\section{Along with the Development of New Technology, New Problems are Confronted by the Fair Use System of Copyright.}

After entering the Internet era, internet information sharing and regional characteristics make the "fair use" of copyright confront new challenges that on one hand, the copyright owners' rights have been greatly expanded, of which the integrity is constantly enhanced, for example, the rise of the Internet makes each copyright owner additionally have a network information dissemination right; on the other hand, the copyright owners' rights are more likely to be damaged, the copyright owners' works can be uploaded to the Internet in a digital form and are very easy to disseminate and copy, and anyone can quickly obtain others' works only through clicking the mouse, so that a possible infringement is generated, and a risk is caused to the protection of copyright owners' rights and interests. As everyone knows that the basic purpose of "fair use" is to encourage the fair use of the existing works to a certain extent for the purpose of promoting further creation; if law and copyright are over-protected, network sharing and free spirit can be violated, so that information dissemination is likely to be impeded, the innovation of the works is not facilitated, and the copyright protection is violated. Therefore, under the situation that the scope of copyright owners' rights and the way of using the works by the public are greatly expanded, it is important to find the balance point between no violation of copyright owners' legitimate interests and maximum utilization of the works by the public.

\section{Several Suggestions on Perfection of China's "Fair Use" System of Copyright}

\section{Insisting on the Tenet of Maintaining "Interest Balance" in the "Copyright Law".}

As the saying goes, "Change is separated from nature". Under complicated modern technology conditions, the perfection of the fair use system of copyright shall always aim to coordinate the balance between copyright owners' individual interests and social public interests; on one hand, taking the protection of the copyright owners' rights and interests as the core; on the other hand, consider social needs, actively and promote the dissemination of literature, art and science in order to meet the public's desire for knowledge exchange and promote cultural prosperity and social progress.

\section{Adopting a Legislative Mode Combining Specific Provisions with Abstract Principles.}

A basic and general guiding principle can be formulated based on existing copyright fair use example regulations so as to adapt to complicated and changeable actual situations and timely regulate the new problems appearing under the new technology conditions. Thus, the fair use system of copyright has better perspectiveness and flexibility, can overcome the defects generated when the example way is adopted, also has a certain right of discretion when the state organs settle specific disputes, so that the work efficiency is improved.

\section{Defining Some Specific Regulations on Fair Use System of Copyright and Properly Adjusting the Scope of Fair Use.}

The quantity standards indefinitely-regulated in the current copyright law shall be converted from qualitative to quantitative, for example, others' published works are used for personal study, research or appreciation. In case of fair use behaviors, there must be a limit on use quantity, so that not only can the purpose of personal use be met, but also others' rights and interests cannot be affected. In addition, in combination with the new characteristics of the network era, the scope and standards of fair use shall be properly adjusted, for example, whether "online education", "digital library", "teaching sound recording or video recording" and other new situations rising along with the development of computer technology can enjoy the fair use right or not shall be strictly defined, and if 
they are for profit, the fair use right cannot be enjoyed, and the copyright owners shall be paid accordingly when their works are used; in aspects of teaching, scientific research and the like which are not for profit, the fair use right should always be encouraged and regarded as a fair use behavior; however, the fair use right shall be properly limited in aspect of number of copies so as to avoid the potential threat caused to the copyright owners' market revenue.

\section{Conclusions}

The fair use system of copyright needs to be constantly improved along with society development, which aims as promoting the widespread dissemination of knowledge and information on the premise of protecting the copyright owners' legitimate rights and interests so as to seek greater spiritual and economic benefits for the society. Certainly, in the works creation process, the fair use must be on the premise of fully respecting others' copyright rights and interests, and when others' works need to be referenced, they must be limited in quantity and scope. In the editing work, editors have responsibilities to supervise and require authors to appropriately reference others' works in manuscripts and specify copyright owners' names and works names and works sources in the references.

\section{References}

[1] Zhao Dongyu: Study on Fair Use System of Copyright under Network Environment [D]. Master's Paper of Ocean University of China, 2006.3

[2] Wang Changlin. Reconstruction of China's Fair Use System under Network Environment [D]. Master's Paper of Southwest University of Political Science and Law, 2006. 4

[3] Zhao Qian. How to grasp the "Degree" of Fair Use with Academic Misconduct Literature Detection System [J]. China Publishing Journal, 2010, 19. 